\title{
ESTIMATION OF VERTICAL DIMENSION OF OCCLUSION IN EDENTULEOUS PATIENTS USING CEPHALOMETRIC ANALYSIS
}

\author{
Ritu Batra ${ }^{1}$, Sanjay Kalra ${ }^{2}$, Ajay Bansal ${ }^{3}$, Siddharth Nerula ${ }^{4}$, Rajat Dang ${ }^{5}$ \\ ${ }^{1}$ Reader, Bhojia Dental College and Hospital, Haryana, India \\ ${ }^{2}$ Senior Prosthodontist, Haryana, India \\ ${ }^{3}$ Reader, Bhojia Dental College and Hospital, Haryana, India \\ ${ }^{4}$ Professor \& HOD, Rajisthan Dental College, Rajasthan, India \\ ${ }^{5}$ Professor, Mullana Dental College, Haryana, India
}

\author{
ABSTRACT \\ "The best of friends fall out with time and so do teeth."
}

Thus, there is a need to replace the lost teeth and the supporting structures for the patient's social demands and functional rehabilitation. Prosthetic treatment with complete dentures is a very common treatment modality; the biggest challenge in its fabrication is to duplicate the normal vertical dimension. Failure can be avoided by completing the treatment without changing the vertical dimension and obtaining an optimal facial proportion. There are many methods to record VD. Radiographic cephalometry has been used as a diagnostic tool in Prosthodontics for over five decades and numerous authors, like Ricketts (1981), McNamara (1984) and Slavicek (1984) developed and computerized these techniques to co-relate and record VD in patients. However cephalometric analysis can help to visualize skeletal and facial proportion relation. The present study was done to use the lateral radiographs with cephalometric analysis, as it could be a simple, nontechnique sensitive, non-invasive and atraumatic way to determine VD for complete denture patients and also to compare physiologic methods (swallowing / phonetics) with cephalometric method to record lower facial height.

Key words : Cephalometrics, Legan-Burstone analysis, Mc Namara analysis, Vertical dimension of rest, Vertical dimension of occlusion, Postural Rest Position.

\section{INTRODUCTION}

Boucher et al stated that "An adequate interocclusal distance is absolutely essential for complete denture patients". The constancy of rest vertical dimension is important because the vertical dimension of occlusion is dependent on it. ${ }^{2}$ Smith claims that eventually "the lips fold inward, furrows and wrinkles are formed and the face becomes prematurely old in appearance".

The value of the lower facial height is routinely estimated by aesthetic analysis

Corresponding Author: Ritu Batra

E-mail: ritubatra71@gmail.com Received: $14^{\text {th }}$ January 2017 Accepted: $20^{\text {th }}$ April 2017 Online: $20^{\text {th }}$ May 2017 and clinical determination of the rest position. Atwood, 1956; Tallgren, 1972; Rugh \& Drago 1981 stated that the rest position is an area rather than a point. The width of comfort zone may vary among individuals and in a single individual at different times, because the individual's capacity is unknown (Rivera-Morales and Mohl, 1991). ${ }^{4}$

Many methods have been proposed to determine the correct Vertical Dimension of Occlusion that include-

i. Vertical dimension of rest (VDR) (Thompson \& Brodie, 1942)

ii. Speaking method (Silverman, 1953)

iii. Cephalometric radiographs (Pyott \& Schaeffer, 1954)

iv. Pre-extraction records (Turner, 1969; Smith, 1971)

v. Maximal bite force (Boos, 1940)

vi. Facial and intra-oral measurements (Willis, 1935; McGee, 1947). 
However, none has been shown to be scientifically more valid than any other (Rivera- Morales \& Moh, 1991) and a lot of them are inexact because they do not consider physiological, age-related facial changes (Koller et al., 1992). ${ }^{5}$ They found that none of them have a sufficient reliability and reproducibility to ensure that the practitioner has recorded the right Vertical Dimension of Occlusion. The soft tissue reference points are not stable and definite; therefore, the use of bony reference points increases the accuracy of the measurements.

The advantages to use cephalometric method for recording VD: ${ }^{6}$

1. Measurement are made on bony points

2. No manipulation of the patient's face is required, once the patient is seated comfortably

2. Concentration is made on the patient and his state of rest, rather than on the measuring device.

3. Permanent record and permanent reference points are available for months or years later.

4. Cephalometric analysis can provide not only the Vertical Dimension of Occlusion but also the orientation of the occlusal plane, the curve of Spee, the anterior teeth position and the anterior guidance (Ismail and Bowman, 1968; L' Estrange and Vig. 1975; Monteith, 1985). 7, 8,9

\section{MATERIAL \& METHOD}

In order to conduct the study twenty two patients between the age group of 50-80 years were randomly selected, from those attending the O.P.D. of the Department of Prosthodontics at B.R.S. Dental College. Thorough case history was recorded and clinical examination was done.

The following criteria were used to include the patients for this study:

1. Edentulous patients were selected at random.

2. Patient's consent was taken before making him a part of the study.

3. Patient who was not an old denture wearer was selected, so that he is not adapted to the old vertical dimensions.

4. Patients with TMJ pain and any mandibular deviation from normal opening pattern were eliminated from the study. ${ }^{10}$
5. Patients only with class I relation were selected. ${ }^{11,12}$ For making radiographic assessment and measuring recordings

1. Cephalostat: The equipment used was Rotograph Plus -VILLA (made in Italy). Automatic mode of exposure time was selected for each patient as per the manufacturer's instructions. Magnification error was uniform for all the subjects (Figure 1B).

2. The lateral Roentgenographic registrations were made on 8 by 10 inch films in cassettes with intensifying screen using mathematical set square (Figure 1C)

3. Acetate tracing paper of 0.003 inch thickness, HB pencil tracing size 0.02 was used for tracing of film and to evaluate the distances between various landmarks (Figure 1A)

\section{METHODOLOGY}

Hard \& soft tissue land marks for Cephalometric Analysis were selected for this study as: ${ }^{13,14,15,16}$. (Figure 2A)

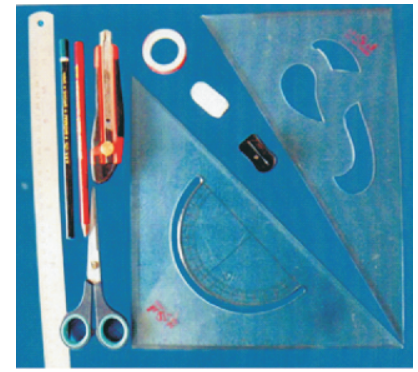

(A)

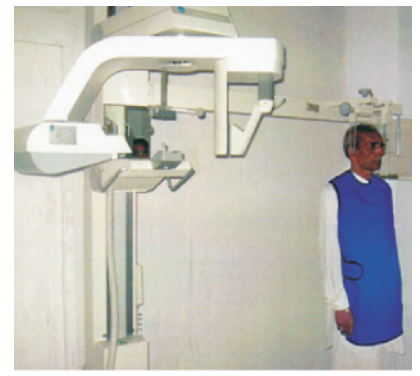

(B)

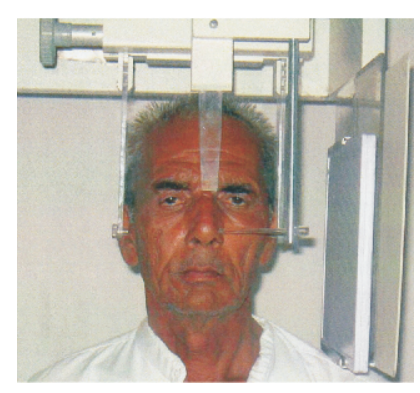

(C)

Figure $1 \mathrm{~A}$ : Measuring devices

B: Cephalostat

C: Patient seated in postural rest position on cephalostat

Hard tissue Landmarks:

1. Sella (S), the mid point of the pituitary fossa.

2. Nasion $(\mathrm{N})$, the most anterior point mid way 
between the frontal and nasal bones on the nasofrontal suture in the midsagittal plane.

3. Facial centre (FC), the intersection of the Frankfurt plane and the perpendicular through the posterior wall of the pterygomaxillary fissure.

4. Subspinale (A), the deepest point in the midsagittal plane between the anterior nasal spine and alveolar crest, usually around the level of and anterior to the apex of the maxillary central incisors.

5. Pogonion $(\mathrm{Pg})$, the most anterior point of the contour of the bony chin in the mid-sagittal plane.

6. Supramentale (B), the deepest point in the midsagittal plane between infradentale and $\mathrm{Pg}$, usually anterior to and slightly below the apices of the mandibular incisors.

7. Anterior nasal spine (ANS), the most anterior point of the nasal floor, the tip of the premaxilla in the midsagittal plane.

8. Menton (Me), the most inferior mid line point on the contour of the mandibular symphysis.

9. Gnathion (Gn), the most anteroinferior point on symphysis. The midpoint between $\mathrm{Pg}$ and $\mathrm{Me}$, located by bisecting the facial line N-Pg and the mandibular plane (lower border).

10. Posterior nasal spine (PNS), the intersection of a continuation of the anterior wall of pterygopalatine fossa and the floor of nose, marking the distal limit of the maxilla (the most posterior point on the contour of the palate).

11. Porion ( $\mathrm{Po}$ ), the midpoint on the upper edge of the external auditory meatus.

12. Condylon(Co), most superior posterior point on condyle

13. Orbitale (Or), the lowest point on the margin of the orbit(Or)

14. Suprapogonion $(\mathrm{Pm})$, point where curvature of the anterior contour of the symphysis changes from concave to convex.
15. Inferior facial height (Xi), the point placed on the center of the mandibular ascending ramus, determined by the Frankfurt plane and pterygomaxillary fissure.

\section{Soft tissue landmarks:}

1. Glabella $(\mathrm{G})$, the most prominent point in the midsagittal plane of the forehead.

2. Subnasion ( $\mathrm{Sn})$, the point at which the nasal septum merges with the upper cutaneous lip in the midsagittal plane

3. Soft tissue menton $\left(\mathrm{Me}^{\prime}\right)$, lowest point on the contour of the soft tissue chin; found by dropping a perpendicular from horizontal plane through menton.

\section{Reference Planes:}

1. Palatal plane: The line through ANS-PNS.

2. Anterior cranial base: The line through N-S.

3. Co-Gn: constructed by a line through the condylon and gnathion obtaining the mandible's length. Height of mandible was correlated accurately for radiographic evaluation as Condylon in posterior compartment shows less distortion. ${ }^{30}$

4. ANS-Xi-Pm: between ANS, Xi, and Pm.

5. Frankfurt's plane: constructed from the lowest point on the margin of the orbit (Or) to the midpoint on the upper edge of the external auditory meatus (Po).

6. Mandibular plane (MP): A plane constructed from menton to the angle of the mandible Go (Downs).

7. Horizontal plane (HP), which is a surrogate Frankfurt plane, constructed by drawing a line 7 degree from the line S to N. Most measurements were made from projections either parallel to HP or perpendicular to HP. All the measurements were made parallel to $\mathrm{HP}^{26,28}$ (The baseline for comparison of most of the data in this analysis is a constructed plane called the Horizontal plane).

8. N-Fc-A: constructed between nasion, facial center and $\mathrm{A}$, used in the determination of the maxillary height.

9. N-ANS-Me: constructed by a vertical line from nasion perpendicular HP to menton. 
10. G-Sn-Me': constructed by a vertical line from Glabella to Menton, perpendicular to HP.

Lateral cephalometric radiographs were obtained at two stages of the study-

1. Before beginning of the treatment

2. After making jaw relation recordings

\section{Step I}

The selected patients were examined and their consent was taken to be a part of the study. Patients were explained the method before beginning of treatment. Every effort was made to prevent the patients from becoming "jaw conscious" or 'rest position conscious. The patients were not "conditioned" through exercises or premedication. A conscious effort was made for the patients, that they are not tensed because, more tense the patient, the less the freeway space tends to be. ${ }^{6,17}$ The first lateral roentgenograph was taken on cephalostat without bite blocks in postural rest position. ${ }^{18}$ The lateral reoentgenographic registrations were made on 8 by 10 inch films in cassettes with intensifying screen. Patients without the dentures in there mouth were made to swallow, wet lips with the tongue and to be perfectly relaxed (Figure 2C)

While in the Cephalostat with the ear plugs lightly placed in the ears. Patients were positioned at postural rest position and were oriented in such a way that $\mathrm{FH}$ plane was parallel to floor. ${ }^{2,3,19}$

Long barrel version of Orbitale indicator was used to ensure horizontal alignment of Orbitale reference with earpieces of ear bow. ${ }^{20}$ In order to control the cumulative tracing errors; tracings were done using semi-transparent acetate paper 0.003 inch. The measurements were made directly on the reoentgenographic film. When the mandible assumed a resting position, the distance from nasion to menton on the rest position films determined vertical dimension at rest measuring the distance between various landmarks. Soft tissue landmarks included upper facial height and lower facial heights were also measured using cephalometric analysis. ${ }^{19}$

\section{$\underline{\text { Step II }}$}

After making preliminary impressions, secondary impressions were made. Denture bases were adapted on casts using self cure acrylic resin (sprinkle on method) and stability of denture bases was checked intraorally. ${ }^{8}$ Patients were made to sit in upright position with the head unsupported and the Frankfurt horizontal plane parallel to the floor. The upper rim was adjusted until it appeared parallel to the camper's plane (centre of the tragus-subnasal point) and the interpupillary axis using a Fox plane and a metal bar. Occlusal plane was adjusted for every patient keeping it parallel to inter pupillary line and ala tragus line. ${ }^{8}$ For registration of vertical dimensions, the phonetic and swallowing method were used in this study because these techniques require the patient to perform simple physiological actions. These methods were readily understood by the patients and easily interpreted. ${ }^{3,18}$ Vertical dimension of rest was recorded by asking patient to keep lips in moderate contact when occlusal rims are out of contact (Nagle and Sears). ${ }^{21}$ and accordingly vertical dimension of occlusion was adjusted. Bite blocks and temporary denture bases were delineated for visibility on radiographs by attaching radio opaque (gutta percha) markers at four places in the second radiograph (Figure 2B).

The marks were placed at

- The midline of upper rim occlusal plane.

- The midline of lower rim at occlusal plane.

- Deepest part of palate in acrylic base of upper rim.

- On the occlusal plane posteriorly.

For the measurements of the vertical dimension of occlusion using functional method second radiograph was taken with bite blocks intraorally and asking the patient to close in centric relation. The vertical dimension of occlusion was measured by measuring the distance from nasion to menton when the maxillary and mandibular bite blocks were in contact. ${ }^{18}$ (Figure 3A). As Pleasure (1951) stated that Vertical dimension of occlusion is approximately $2 \mathrm{~mm}$ lower than vertical dimension of rest. To make the two $\mathrm{x}$-ray films compatible for measurements of lower facial height (vertical dimension of occlusion) $2 \mathrm{~mm}$ was reduced 


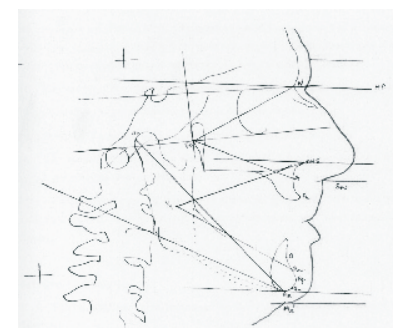

(A)

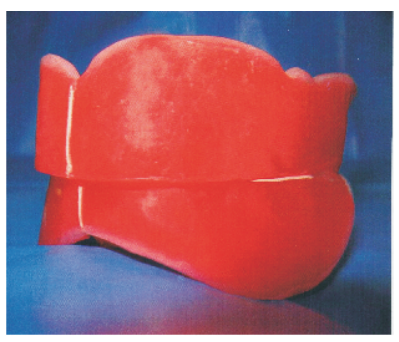

(B)

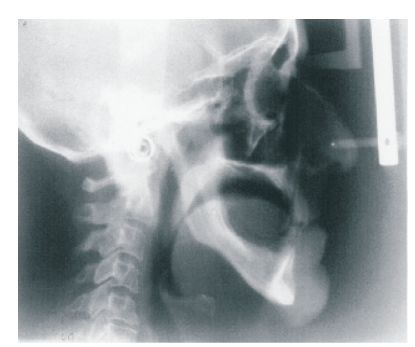

(C)

Figure $2 \mathrm{~A}$ : Cephalometric land marks for hard tissue and soft tissue tracings

B: Occlusal rims with radio- opaque markers

$\mathrm{C}$ : Radiographic film in postural rest position without occlusal rims

from the measurements in the first x-ray film. The soft tissue facial profile is closely related to and dependent on the underlying skeletal structure, so soft tissue as well as skeletal measurements were done simultaneously as per Rickets, McNamara (for skeletal), Legan-Burstone analysis (for soft tissue). ${ }^{22}$

\section{RESULTS ANDDISCUSSION}

Statistical Analysis was done to evaluate the difference between the cephalometric method and functional method, and also to evaluate the reliability of cephalometric method. The observations were compared with the normal values given by McNamara analysis. On every individual two observations were recorded:

CRwor: cephalometric postural rest position without occlusal rims ( $1^{\text {st }}$ method).

Fwr: functional method with occlusal rims $\left(2^{\text {nd }}\right.$ method).

Data was collected on twenty two individuals giving us twenty two paired observations. The data was statistically evaluated; box plot of the data was made in SPSS to see how the skeletal and soft tissue proportions for these two methods were distributed.

\section{Mandibular length of each patient with cephalometric postural rest position without occlusal rims and functional method with occlusal rims $(\mathrm{Co}-\mathrm{Gn})$ in $\mathbf{m m}$ (Table 1$)$}

Table 1: Mandibular length of each patient with cephalometric postural rest position without occlusal rims and functional method with occlusal rims $(\mathrm{Co}-\mathrm{Gn})$ in $\mathrm{mm}$

\begin{tabular}{|l|l|l|}
\hline S NO. & CR wor & F wr \\
\hline 1 & 136 & 140 \\
\hline 2 & 122 & 120 \\
\hline 3 & 135 & 136 \\
\hline 4 & 125 & 124 \\
\hline 5 & 128 & 121 \\
\hline 6 & 124 & 122 \\
\hline 7 & 133 & 134 \\
\hline 8 & 126 & 127 \\
\hline 9 & 130 & 132 \\
\hline 10 & 128 & 125 \\
\hline 11 & 128 & 128 \\
\hline 12 & 101 & 101 \\
\hline 13 & 120 & 125 \\
\hline 14 & 114 & 115 \\
\hline 15 & 115 & 120 \\
\hline 16 & 118 & 119 \\
\hline 17 & 116 & 113 \\
\hline 18 & 120 & 117 \\
\hline 19 & 135 & 134 \\
\hline 20 & 121 & 121 \\
\hline 21 & 128 & 126 \\
\hline 22 & 124 & 124 \\
\hline
\end{tabular}

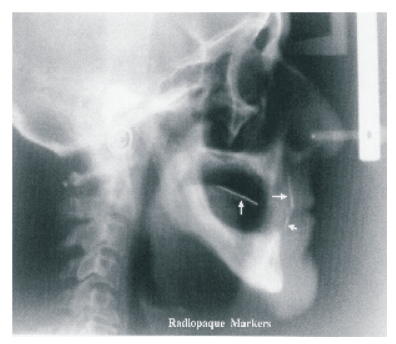

(A)

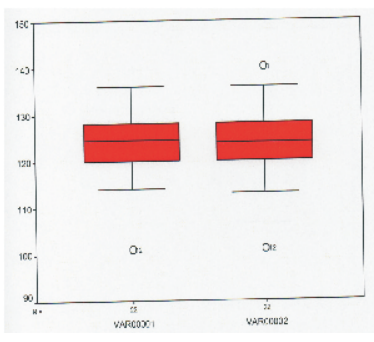

(B)

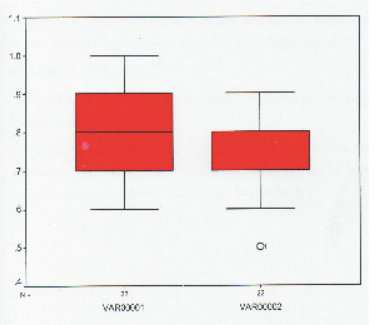

(C)

Figure 3 (A): Radiographic film with radioopaque markers on occlusal rims

B: Box plot 1, mandibular length

C: Box plot2, skeletal proportions 
$($ Normal values male $=130 \mathrm{~mm}$, Female $=120 \mathrm{~mm})$.

An average value found with both methods = 123.95 mm.(box plot-1: Fig 3B)

Skeletal proportion between the middle and lower third of the head for each patient with cephalometric evaluation and functional method (vertical dimension of occlusion) N-ANS: ANS-Me (Table 2).

(Normal values $=0.8 \pm 0.2)^{23,24,25}$

The median value of skeletal proportions in box plot 2 ; for $1^{\text {st }}$ method $=0.8$

$2^{\text {nd }}$ method $=0.75$. (box plot-2: Figure $3 \mathrm{C}$ )

Table 2: Skeletal proportion between the middle and lower third of the head for each patient with cephalometric evaluation and functional method (vertical dimension of occlusion) N-ANS: ANS$\mathrm{Me}$

\begin{tabular}{|c|l|l|l|l|}
\hline S No. & Crwor & Proportions & Fwr & Proportion \\
\hline 1 & $50 / 66$ & 0.757 & $50 / 86$ & 0.581 \\
\hline 2 & $54 / 57$ & 0.947 & $55 / 65$ & 0.846 \\
\hline 3 & $57 / 60$ & 0.950 & $59 / 69$ & 0.855 \\
\hline 4 & $56 / 66$ & 0.848 & $55 / 71$ & 0.775 \\
\hline 5 & $57 / 65$ & 0.877 & $53 / 70$ & 0.757 \\
\hline 6 & $54 / 63$ & 0.857 & $53 / 61$ & 0.869 \\
\hline 7 & $54 / 68$ & 0.794 & $53 / 75$ & 0.707 \\
\hline 8 & $55 / 60$ & 0.916 & $56 / 64$ & 0.843 \\
\hline 9 & $48 / 74$ & 0.648 & $51 / 76$ & 0.671 \\
\hline 10 & $54 / 82$ & 0.658 & $54 / 80$ & 0.675 \\
\hline 11 & $59 / 71$ & 0.831 & $58 / 71$ & 0.817 \\
\hline 12 & $48 / 58$ & 0.827 & $50 / 55$ & 0.909 \\
\hline 13 & $60 / 58$ & 1.034 & $60 / 66$ & 0.909 \\
\hline 14 & $51 / 63$ & 0.809 & $49 / 67$ & 0.731 \\
\hline 15 & $59 / 64$ & 0.922 & $57 / 65$ & 0.877 \\
\hline 16 & $49 / 52$ & 0.942 & $49 / 54$ & 0.907 \\
\hline 17 & $50 / 58$ & 0.862 & $54 / 60$ & 0.900 \\
\hline 18 & $52 / 56.5$ & 0.920 & $50 / 58$ & 0.862 \\
\hline 19 & $52 / 78$ & 0.666 & $53 / 75$ & 0.707 \\
\hline 20 & $52 / 71.5$ & 0.727 & $52 / 67.5$ & 0.770 \\
\hline 21 & $58 / 73$ & 0.795 & $55 / 76$ & 0.724 \\
\hline 22 & $60 / 71$ & 0.845 & $57 / 70$ & 0.814 \\
\hline & & & & \\
\hline
\end{tabular}

Skeletal proportions for the $1^{\text {st }}$ method were found to be more around 0.8 as compared to the $2^{\text {nd }}$ method. As such $1^{\text {st }}$ method seems to be close to McNamara Analysis.
Soft tissue proportion for each patient with cephalometric evaluation and functional method (vertical dimension of occlusion) G-Sn: Sn-Me' (Table 3)

(Normal value $=1.0 \pm 0.2) ., 23$

Median value $1^{\text {st }}$ method=1.0

$$
2^{\text {nd }} \text { method }=1.0 \text { (box plot-3: Fig 4A) }
$$

Angle of middle third of head $<$ NFcA in degrees (Table 4)

$\left(\right.$ Normal value $\left.=53^{\circ}\right)$.,23 $^{7,23}$

Median value, $1^{\text {st }}$ method $=55^{\circ}$

$$
\left.2^{\text {nd }} \text { method }=54^{\circ} \text { (box plot-4:Fig } 4 B\right)
$$

\section{FOR < ANS X1 PM (Table 5)}

$\left(\right.$ Normal value $\left.=47^{\circ}\right){ }^{7,23}$

Median value in both methods is $47^{\circ}$ (box plot-5: Figure 4C)

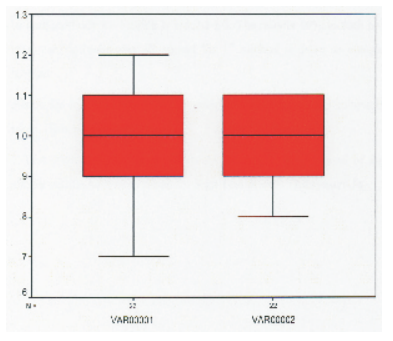

(A)

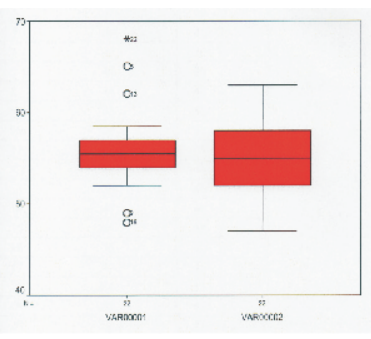

(B)

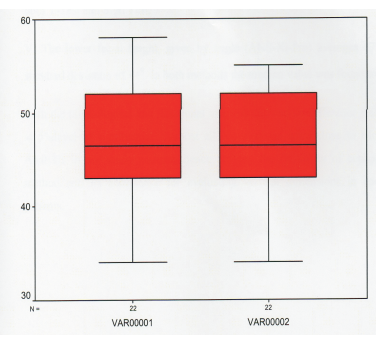

(C)

Figure 4 (A): Box plot 3, soft tissue analysis

(B): Box plot 4, Mid facial angle

(C): Box plot 5, lower facial angle

The VDR has been considered as a reference position for the value of VDO, clinically being set by the tonic muscular activity. If the vertical dimension is reduced, there will be a loss of muscular power, and marked changes in facial expression will occur. The muscles of mastication and facial expression are shortened, the anatomic angulation between their 
Table 3: Soft tissue proportion for each patient with cephalometric evaluation and functional method (vertical dimension of occlusion) G-Sn: Sn-Me'

\begin{tabular}{|l|l|l|l|l|}
\hline S no & CR Wor & Pro & Fwr & Pro \\
\hline 1 & $78 / 79$ & 0.987 & $77 / 88$ & 0.875 \\
\hline 2 & $78 / 74$ & 1.054 & $79 / 75$ & 1.053 \\
\hline 3 & $72 / 69$ & 1.043 & $76 / 77$ & 0.987 \\
\hline 4 & $68 / 77$ & 0.883 & $66 / 81$ & 0.815 \\
\hline 5 & $75 / 68$ & 1.103 & $75 / 69$ & 1.086 \\
\hline 6 & $73 / 66$ & 1.106 & $74 / 64$ & 1.156 \\
\hline 7 & $82 / 65$ & 1.261 & $81 / 70$ & 1.157 \\
\hline 8 & $74 / 59$ & 1.254 & $74 / 64$ & 1.156 \\
\hline 9 & $66 / 79$ & 0.835 & $64 / 80$ & 0.8 \\
\hline 10 & $83 / 83$ & 1.0 & $77 / 81$ & 0.951 \\
\hline 11 & $80 / 73$ & 1.096 & $81 / 72.5$ & 1.117 \\
\hline 12 & $66 / 65$ & 1.105 & $68 / 63$ & 1.079 \\
\hline 13 & $80 / 66$ & 1.212 & $79 / 70$ & 1.128 \\
\hline 14 & $66 / 65$ & 1.015 & $67 / 69$ & 0.971 \\
\hline 15 & $77 / 72$ & 1.069 & $78 / 70$ & 1.114 \\
\hline 16 & $64 / 58$ & 1.103 & $65 / 60$ & 1.083 \\
\hline 17 & $72 / 60$ & 1.2 & $66 / 64$ & 1.031 \\
\hline 18 & $62.5 / 62.5$ & 1.0 & $63.5 / 64$ & 0.992 \\
\hline 19 & $65 / 82$ & 0.793 & $66 / 82$ & 0.804 \\
\hline 20 & $72.5 / 73.5$ & 0.986 & $75.5 / 69.5$ & 1.086 \\
\hline 21 & $71 / 75$ & 0.946 & $71 / 70$ & 1.014 \\
\hline 22 & $75 / 75$ & 1.0 & $77 / 75$ & 1.026 \\
\hline & & & &
\end{tabular}

Table 4: Angle of middle third of head $<$ NFcA in degrees

\begin{tabular}{|c|c|c|}
\hline S No. & CRwor & Fwr \\
\hline 1 & 55 & 56 \\
\hline 2 & 58.5 & 57.5 \\
\hline 3 & 55 & 55 \\
\hline 4 & 57 & 58 \\
\hline 5 & 65 & 63 \\
\hline 6 & 56 & 54 \\
\hline 7 & 56 & 55 \\
\hline 8 & 58 & 59 \\
\hline 9 & 49 & 51 \\
\hline 10 & 56 & 55 \\
\hline 11 & 56 & 56 \\
\hline 12 & 55 & 58 \\
\hline 13 & 62 & 59 \\
\hline 14 & 54 & 51 \\
\hline 15 & 57 & 56 \\
\hline 16 & 48 & 47 \\
\hline 17 & 55 & 58 \\
\hline 18 & 52 & 50 \\
\hline 19 & 53 & 53 \\
\hline 20 & 53 & 52 \\
\hline 21 & 55 & 49.5 \\
\hline 22 & 68 & 54 \\
\hline
\end{tabular}

Table 5: Angle of lower third of head $<$ ANS Xi Pm in degrees

\begin{tabular}{|c|c|c|}
\hline S NO. & CRwor & Fwr \\
\hline 1 & 55 & 52 \\
\hline 2 & 56 & 55 \\
\hline 3 & 40 & 55 \\
\hline 4 & 47 & 49 \\
\hline 5 & 46 & 48 \\
\hline 6 & 43 & 39 \\
\hline 7 & 46 & 50 \\
\hline 8 & 44 & 43 \\
\hline 9 & 52 & 52 \\
\hline 10 & 55 & 54 \\
\hline 11 & 43 & 43 \\
\hline 12 & 49 & 44 \\
\hline 13 & 38 & 40 \\
\hline 14 & 47 & 48 \\
\hline 15 & 44 & 38 \\
\hline 16 & 35 & 35 \\
\hline 17 & 44 & 45 \\
\hline 18 & 34 & 34 \\
\hline 19 & 47 & 44 \\
\hline 20 & 50.5 & 43 \\
\hline 21 & 52 & 52 \\
\hline 22 & 58 & 53 \\
\hline
\end{tabular}

points of origin and insertion is changed, and they are unable to exert their maximum tension. This decreased tension, in turn, causes them to loose tone, just as any muscle tissue does when it does not receive enough exercise. Decreasing the free way space beyond the physiologic limits of the muscles (increase in vertical dimension) also results in a diminished masticatory power because the muscles are in a continual state of strain, the patient feels uncomfortable, and he cannot find the cause. During speech, patients may become adjusted to a decreased vertical dimension but almost never to an increased vertical dimension. ${ }^{3}$ According to MoHL (1978), McNamara et al. (1978) resting vertical dimension including the freeway space, is an adaptive physiologic parameter. McNamara stated that the rest position is influenced by the activity of the fusimotor system of the elevator muscles through psychic input and through stimuli from peripheral receptors such as those located in the temporomandibular joint, periodontal ligament, gingiva, tongue, and palate. In 
the present study radiographs taken at two stages showed a difference between both readings representing the free way space, but did not affect the facial proportions, and allowed for appropriate phonetics and esthetics. This suggests that the functional method traditionally used complimented the cephalometric method to determine VDO in edentulous patients.

\section{LIMITATIONS:}

1. The main limitation of using the rest position to determine the vertical dimension of occlusion is that the jaw postural position is not constant but varies continuously. ${ }^{8}$

2. The cephalometric method for positioning the anterior teeth in complete denture is not suitable for routine use. Incisor position is seen outside2 standard deviation, from average Ricketts' data for dentate subjects. ${ }^{10}$

3. The patients with class II, class III relations were eliminated from the study because they show positive correlations between vertical height, mandibular morphology, mandibular plane angulation which is high. ${ }^{19}$

4. The increase in the Nasolabial angle (NLA) is associated closely with increase in the vertical dimension of the face. The NLA increases with the amount of maxillary incisor retraction. ${ }^{22}$

5. The mandibular rest position is influenced by the presence or absence of dentures. There is lowering of rest position of mandible upon insertion of dentures or patients may raise the mandibular rest position after insertion. The resting vertical dimension is often different depending on whether the dentures are in or out of the mouth. ${ }^{6},{ }^{21}$

\section{CONCLUSION}

In this study, there was stability in the skeletal vertical dimension, corroborating that the proportion of $0.8 \pm 0.2$ was present between N-ANS and ANS-Me. Statistically no significant difference was found when comparing the measurement of $1^{\text {st }}$ method with the $2^{\text {nd }}$ method. In the second method the lower facial height was observed to be on the higher side in comparison with $1^{\text {st }}$ method but the increase in vertical dimension of occlusion after insertion of occlusal rims in the $2^{\text {nd }}$ method could lead to the increased lower facial height. ${ }^{6,27,28}$ It was found that soft tissue proportion was maintained at around $1 \pm 0.2 \mathrm{~mm}$, and this was observed in both methods. Both the physiological and functional methods showed no difference statistically at $+5 \%$ level of significance. Almost all observations were close to McNamara Analysis in our study patients, hence proving the reliability of cephalometric method and its acceptance for evaluating vertical dimensions in edentulous patients. These findings support the claim that the cephalometric method is a reliable and appropriate method for estimating the vertical dimensions in edentulous patients and can be used routinely by prosthodontist to confirm the vertical dimensions in combination with other methods.

\section{REFERENCES}

1. Zarb-Bolender et al. Prosthodontic treatment for edentulous patients.12th ed. 2004, Mosby, West line Industril Drive,St.Louis MO:268-97.

2. Jayashree V Dikshit and Firoze D Mirza. Muscle relaxant and rest position - A cephalometric Study. J Prosthet Dent 1979;42:579-83.

3. Alex Coulouriotes. A.B. Free Way Space. J Prosthet Dent 1955; 5:194-9.

4. J.D. Orthlieb, M Laurent and O Laplanche. Cephalometric estimation of Vertical Dimension of Occlusion. J Oral Rehabil 2000;27:802-7.

5. C Millet, C Jeannin, B Vincent \& G Malquarti. Report on the determination of occlusal vertical dimension and centric relation using swallowing in edentulous patients. J Oral Rehabil 2003;30:1118-22

6. Douglas Allen Atwood. A cephalometric study of the clinical rest position of the mandible. Part I. The Variability of the Clinical Rest Position following the Removal of Occlusal Contacts. J Prosthet Dent 1955;10:504-9.

7. Brian D Monteith. A cephalometric method to determine the angulation of the occlusal plane in edentulous patients. J Prosthet Dent 1985;54:81-7.

8. M M Koller, L Merlini, G Spandre and S Palla. A comparative Study of two methods for the orientation of the occlusal plane and the determination of the vertical dimension of occlusion in edentulous patients. J Oral Rehabil 1992;19:413-25.

9. Jay P Fitzgerald, Ram S Nanda, G Frans Currier. An evaluation of the nasolabial angle and the relative inclinations of the nose and upper lip. Am J Orthod Dentofac Orthop 1992;102:328- 
34.

10. Ales Obrez, Jens C Turp. The effect of musculosketal facial pain on registration of maxillomandibular relationships and treatment planning: A synthesis of the literature. J Prosthet Dent 1998;79:194-9.

11. H W Preiskel. Some observations on the postural position of the mandible. J Prosthet Dent 1965;15:625-33.

12. Robert S Freeman. Adjusting A-N-B Angles to Reflect the Effect of Maxillary Position. Angle Orthod 1981;51(2):16271.

13. Charles J Burstone, Randal B James, H Legan, G A Murphy, and Louis A Norton. Cephalometrics for Orthognathic surgery. J Oral Surg1978;36:269-77.

14. Dr. S I Bhalajhi. Orthodontics, The Art and Science. 2nd ed. Arya (Medi) Publishing house, Darya Ganj, New Delhi 2001;148-50.

15. Athanasios E Athanasiou. Orthodontic Cephalometry.1995 Mosby-Wolfe, Times Mirror International Publishers Limited.

16. Thomas Rakosi. An Atlas and Manual of Cephalometric Radiography. 1982 Lea \& Febiger- 600 Washington Square, Philadelphia, Pennsylvania 19106 USA

17. Glenn L Gittelson. Vertical Dimension of Occlusion in Implant Dentistry: Significance and Approach. Implant Dentistry 2002;2:33-8.

18. Herbert Swerdlow, B A, Bethesda. Roentgencephalometric Study of Vertical Dimension Change in Immediate Denture patients. J Prosthet Dent 1964;14:635-49.

19. H W Preiskel. Some observations on the postural position of the mandible. J Prosthet Dent 1965;15:625-33.
20. Brian D Monteith. Cephalometrically programmed adjustable plane: A new concept in occlusal plane orientation for complete denture patients. J Prosthet Dent 1985;54:388-94.

21. Allen M Kleinman and Irving M Sheppard. Mandibular rest levels with and without dentures in place in edentulous and complete denture wearing subjects. J Prosthet Dent 1972; 28:478-83.

22. Franklin D Lo and W Stuart Hunter. Changes in Nasolabial angle related to maxillary incisor retraction. Am J Orthod 1982;82:384-90.

23. D Brzoza, N Barrera, G Contasti and A Hernandez. Predicting vertical dimension with cephalograms,for edentulous patients. Gerodontology 2005;22:98-103.

24. Charles J Burstone, Randal B James, H Legan, G A Murphy, and Louis A Norton. Cephalometrics for Orthognathic surgery. J Oral Surg1978;36:269-77.

25. Robert M Ricketts. Perspective in the Clinical Application of Cephalometrics: The first fifty years. The Angle Orthod 1981;51:115-47.

26. F Bassi, A Rizzatti, G Schierano \& G Pret. Evaluation of the utility of cephalometric parameters in constructing complete denture. Part-II: placement of anterior teeth. J Oral Rehabil 2001;28:349-453.

27. Geroge A Wessberg, Michael C Washburn, Frace N Epker and Kent O Dana. Evaluation of mandibular rest position in subjects with diverse dentofacial morphology. J Prosthet Dent 1982;48:451-9.

28. Franklin D Lo and W Stuart Hunter. Changes in Nasolabial angle related to maxillary incisor retraction. Am J Orthod 1982;82:384-90. 